\title{
Evaluation of onset of pain relief from micronized aspirin in a dental pain model
}

\author{
S. A. Cooper $\cdot$ M. Voelker
}

Received: 13 September 2011/ Accepted: 7 January 2012/Published online: 29 January 2012

(C) The Author(s) 2012. This article is published with open access at Springerlink.com

\begin{abstract}
A new formulation of a micronized acetylsalicylic acid swallowable tablet with an effervescent component (FR-aspirin) was evaluated in two independent studies using the dental impaction pain model. These clinical studies were performed to confirm the results of preclinical dissolution studies and human pharmacokinetic studies, which indicated an improved onset of analgesia without compromising duration of effect or safety. Study 1 evaluated a 650-mg dose of aspirin and Study 2 evaluated a 1,000-mg dose of aspirin. Both studies were double-blinded, parallel group and compared to regular aspirin (R-aspirin) and placebo. Speed of onset was measured by the double stopwatch method for time to both first perceptible relief and meaningful relief. In both studies, the FR-aspirin was significantly faster $(p<0.038-0.001)$ than both R-aspirin and placebo for both onset measures. There were no significant differences between FR-aspirin and $\mathrm{R}$-aspirin for peak or total effects and both treatments were significantly better than placebo. For first perceptible relief, FR-aspirin onset was 19.8 and $16.3 \mathrm{~min}$ for $650 \mathrm{mg}$ and $1,000 \mathrm{mg}$, respectively, compared to 23.7 and 20.0 for $\mathrm{R}$-aspirin. For meaningful relief, FR-aspirin onset was 48.9 and $49.4 \mathrm{~min}$ for $650 \mathrm{mg}$ and $1,000 \mathrm{mg}$, respectively, compared to 119.2 and 99.2 for R-aspirin. These efficacy studies clearly demonstrate that the onset of analgesic efficacy is dramatically improved by adding an effervescent
\end{abstract}

S. A. Cooper

Clinical Trial Consultant, Palm Beach Gardens, FL, USA

M. Voelker

Bayer Consumer Care, Morristown, NJ, USA

M. Voelker ( $\square)$

Bayer HealthCare, Building K56, 51368 Leverkusen, Germany

e-mail: michael.voelker@bayer.com component and micronized active ingredient to the swallowable tablet aspirin formulation. The enhanced onset did not adversely impact either the peak effect or duration of effect or tolerability compared to regular aspirin.

Keywords Aspirin - Acetylsalicylic acid .

Onset of action - Dental pain - Acute pain

\section{Introduction}

The two efficacy studies described in this paper were conducted to evaluate the speed of relief onset from a new aspirin swallowable tablet formulation compared to regular aspirin. Based on the improved dissolution and pharmacokinetic profile, the expectation was that this formulation would have a clinically meaningful advantage in time to onset of pain relief.

Self-treatment of acute mild-to-moderate pain with over-the-counter (OTC) analgesics is well established in the general population. Aspirin (acetylsalicylic acid, ASA) is one of the most commonly used analgesics worldwide for this purpose. Its efficacy has been shown in several acute pain conditions, including tension-type headache (Steiner et al. 2003; Martinez-Martin et al. 2001; MacEachern et al. 2002), migraine headache (MacGregor et al. 2002; Lange et al. 2000; Diener et al. 2004a, b, 2006; Lipton et al. 2005; Lampl et al. 2007), sore throat (Eccles et al. 2003), primary dysmenorrhea (Zhang and Li Wan Po 1998) and dental pain (Forbes et al. 1991, 1992; Cooper 1981a, b), as well as fever (Bachert et al. 2005).

The key domains recognized by consumers for an efficacious acute analgesic are fast onset, long duration and complete pain relief. Fast onset of action is of particular importance in an outpatient, self-medication environment. 
Several pain models have been performed to assess pain relief and onset of relief (Cooper 1983); however, the Dental Impaction Pain Model (DIPM) is the most well established. The sensitivity, reproducibility and reliability of this model are well documented (Cooper and Desjardins 2010; Desjardins et al. 2002). The American Food and Drug Administration and the European Medicines Agency both identified the third molar extraction dental pain model as acceptable for assessing analgesia in acute mild-tomoderate pain (Food and Drug Administration 1977; European Medicines Agency 2002).

A novel aspirin formulation with an effervescent component consisting of sodium carbonate and micronized active ingredient has been developed. This new swallowable tablet formulation has been shown to decrease substantially the in vitro dissolution time and in vivo time to maximum plasma concentration The small active ingredient particle size provides a much larger surface area than the Aspirin ${ }^{\circledR}$ regular tablet resulting in faster dissolution and consequently faster in vivo absorption (Voelker 2011).

Two tablet strengths of the new formulation fast release (FR-aspirin) contain either 325 or $500 \mathrm{mg}$ aspirin, resulting in a total dose of either 650 or $1,000 \mathrm{mg}$. In these two efficacy studies, we investigated whether the pharmaceutical and pharmacokinetic properties were associated with a faster onset of pain relief compared to a corresponding strength of regular Aspirin ${ }^{\circledR} 325 \mathrm{mg}$ or $500 \mathrm{mg}$ (R-aspirin).

\section{Methods}

The studies were designed to evaluate the analgesic efficacy of a single, oral dose of FR-aspirin tablets compared to R-aspirin tablets and placebo in subjects with postsurgical pain resulting from the surgical removal of impacted third molars. Patients were required to have one of the following surgical procedures: either two partial bony impacted mandibular third molars, one full bony impacted mandibular third molar, or one partial bony impacted and one fully bony impacted mandibular third molars removed. Additionally, any maxillary third molars could have been removed regardless of impaction level.

Each study was conducted at a single study site. For Study 1, the treatment arms were: placebo, R-aspirin $1,000 \mathrm{mg}$, FR-aspirin 1,000 mg. For Study 2, the treatment arms were: placebo, R-aspirin $650 \mathrm{mg}$, FR-aspirin $650 \mathrm{mg}$. Both were randomized, double-blind, parallel group and single-dose studies. The randomization scheme in both studies was 2:2:1 for the ratio of active drugs to placebo. Because the FR-aspirin and R-aspirin tablets were not identical in appearance, subjects had a blinding device applied and the study drugs were administered by a third party who was not otherwise involved in the conduct of the study. The aspirin comparator was commercially available Aspirin ${ }^{\circledR}$ regular tablet $500 \mathrm{mg}$ or Bayer Aspirin ${ }^{\circledR} 325 \mathrm{mg}$ tablets (both Bayer HealthCare, Germany).

Studies were conducted according to the principles of the International Conference on Harmonisation Harmonised Tripartite Guideline E6(R1): Good Clinical Practice (GCP), the World Medical Association Declaration of Helsinki and its most recent amendments, and United States Title 21 of the Code of Federal Regulations Parts 50 and 56 concerning informed consent and IRB regulations. Written informed consent was obtained from each subject at screening before the initiation of any study-related procedures.

Patients were included in the studies if they had moderate or severe postsurgical pain within $1-4 \mathrm{~h}$ after surgery and a score of $\geq 5$ on the 11-point numerical pain intensity rating scale $(\mathrm{NRS})(0=$ no pain to $10=$ very painful $)$.

Patients were provided with two stopwatches starting at study drug administration: the first was stopped when they first felt any perceptible pain relief and the second was pressed when they felt pain relief that was in their estimation meaningful. The patients recorded pain intensity (PI) and pain relief (PR) at 10, 20, 30, 40, 50 and $60 \mathrm{~min}$ and at 2, 3, 4, 5 and $6 \mathrm{~h}$ after dosing. PI was rated on a four-point categorical pain intensity scale $(0=$ no pain, $1=$ mild pain, $2=$ moderate pain, $3=$ severe pain); PR was rated using a five-point categorical pain relief rating scale $(0=$ no relief, $1=\mathrm{a}$ little relief, $2=$ some relief, $3=a$ lot of relief, and $4=$ complete relief). At the 6-h observation or at the time of rescue analgesic if it occurred prior to the 6th $\mathrm{h}$ observation, subjects completed a five-point categorical global evaluation of the study drug $(0=$ poor, $1=$ fair, $2=$ good, $3=$ very good, and $4=$ excellent). Rescue medication was Lortab 5 (hydrocodone $5 \mathrm{mg} /$ acetaminophen $500 \mathrm{mg}$ ) tablets. Adverse events were monitored and recorded throughout the dosing period. After completion of the dosing period, the study sites had the option of either contacting subjects within 2-5 days or scheduling subjects for a follow-up office appointment to assess surgical healing, the occurrence or persistence of adverse events and medications taken. The primary efficacy end point was time to first perceptible pain relief. Secondary variables were time to meaningful PR, PI and PI differences, summed pain intensity differences (SPID) and total pain relief (TOTPAR) values at 2, 4 and $6 \mathrm{~h}$ and global evaluation.

Statistical analysis

A sample size calculation for each study of approximately 500 subjects (200 subjects per aspirin treatment group and 
100 subjects in the placebo group) provided $90 \%$ power to detect a treatment difference between FR-aspirin and $\mathrm{R}$-aspirin for time to pain relief at a two-sided significance level of 0.05 .

All hypotheses were tested at a two-sided significance level of 0.05. Efficacy variables were analyzed using all randomized subjects who took the study drug and who had at least one post-dose assessment on an efficacy parameter (intent to treat).

Time to first perceptible PR and meaningful PR were plotted using the Kaplan-Meier method and compared between treatment groups using the log-rank test. Median times to first perceptible PR and meaningful PR were calculated and presented.

Time-weighted SPIDs and TOTPARs were calculated for $6 \mathrm{~h}$. An analysis of covariance (ANCOVA) model was used to compare means across treatment groups for the following secondary efficacy end points: $\mathrm{SPID}_{0_{-2}}, \mathrm{SPID}_{0-4}$,

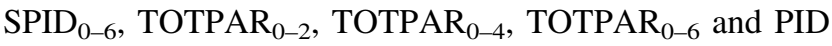
at each post-dose time point. The ANCOVA model included treatment and center as the fixed effects and baseline pain as the covariate. In each analysis, adjusted least squares (LS) mean standard error and LS mean difference, along with $95 \%$ confidence intervals (CIs) of the difference, were obtained from the model.

\section{Results of Study 1: $500 \mathrm{mg}$ aspirin tablet}

Efficacy evaluations were made on the basis of the 514 patients included in the intent-to-treat (ITT) population for Study 1 (500 mg of aspirin). There were no group differences with respect to age, gender and baseline pain intensity (Table 1). The majority of patients were of younger age with a range of means of 22.4-22.7 years for the three treatment groups. At baseline, the overall mean PI score was 6.6 on the 11-point NRS. Approximately, $80 \%$ of patients in this study graded their baseline pain as moderate and $20 \%$ as severe. Approximately, three-quarters of the patients underwent removal of two impacted mandibular molars with a majority of patients having a total of three molars removed (Table 1).

Kaplan-Meier plots of time to first perceptible pain relief and meaningful pain relief showed a statistically significant difference between FR-aspirin tablets and R-aspirin tablets $(p<0.05)$. Both active treatments were significantly faster than placebo $(p<0.001)$ (Figs. 1, 2; Table 2). Median time to first perceptible pain relief was $16.3 \mathrm{~min}$ for FR-aspirin $500 \mathrm{mg}$ and $20.0 \mathrm{~min}$ for R-aspirin $500 \mathrm{mg}$. Median time to meaningful pain relief was $49.4 \mathrm{~min}$ for FR-aspirin versus $99.2 \mathrm{~min}$ for $\mathrm{R}$-aspirin. A higher percentage of patients in the FR-aspirin group achieved pain relief compared to $\mathrm{R}$-aspirin and placebo (first perceptible pain relief: 92.2 vs. 85.7 vs. $70.5 \%$ and meaningful relief: 65.0 vs. 62.1 vs. $37.1 \%$ ).

The SPID and TOTPAR results were consistent with the greater efficacy for the FR-aspirin compared to the R-aspirin and placebo. At $2 \mathrm{~h}$, differences between FRaspirin and R-aspirin were significant $[p=0.026$ (SPID) and $p=0.018$ (TOTPAR)] and both actives were statistically superior compared with placebo $(p<0.001)$. For the 4- and 6-h measurements, SPID and TOTPAR for the FRaspirin and R-aspirin were not different from each other, but both were statistically significantly greater than placebo (Table 2).

With respect to the global evaluation, the majority of subjects treated with FR-aspirin and R-aspirin rated their treatment as "fair" or better; while the majority of subjects treated with placebo rated their treatment as poor. More subjects treated with FR-aspirin assessed as very good or excellent (18.0 and 6.3\%) compared with R-aspirin [13.8 and $5.4 \%$ (Table 3 )].

Both active treatments were well tolerated. No serious adverse events were reported and no subject was discontinued due to adverse event in either $500 \mathrm{mg}$ aspirin treatment group.

\section{Results of Study 2: $325 \mathrm{mg}$ aspirin tablet}

Efficacy evaluations were made on the basis of the 500 patients included in the intent-to-treat (ITT) population for Study 2 (325 mg aspirin). There were no group differences with respect to age, gender and baseline pain intensity (Table 1). The majority of patients were of younger age with a range of means of 20.3-20.8 years for the three treatment groups. At baseline, the overall mean PI score was 7.4 on the 11-point NRS. Approximately, 57\% of patients graded moderate baseline pain and $43 \%$ severe baseline pain. Approximately, three-quarters of patients underwent removal of two impacted mandibular molars with a majority of patients having a total of four molars removed (Table 1).

Kaplan-Meier plots of time to first perceptible pain relief and meaningful pain relief showed a statistically significant difference between FR-aspirin tablets and R-aspirin tablets $(p<0.05)$. Both active treatments were significantly faster than placebo $(p<0.001)$ (Figs. 1, 2; Table 2). Median time to first perceptible pain relief was $19.8 \mathrm{~min}$ for FR-aspirin $325 \mathrm{mg}$ and $23.7 \mathrm{~min}$ for R-aspirin $325 \mathrm{mg}$. In this study, median time to meaningful pain relief was $48.9 \mathrm{~min}$ for FR-aspirin versus $119.2 \mathrm{~min}$ for $\mathrm{R}$-aspirin. A higher percentage of patients in the FR-aspirin group achieved pain relief compared to $\mathrm{R}$-aspirin and placebo (first perceptible pain relief: 95.0 vs. 85.0 vs. $62.0 \%$ and meaningful relief: 72.5 vs. 59.0 vs. $30.0 \%$ ). 
Table 1 Summary of demographics and baseline characteristics

\begin{tabular}{|c|c|c|c|c|}
\hline Study & Variable & Aspirin fast-release tablet & Aspirin regular tablet & Placebo \\
\hline \multirow[t]{21}{*}{500 mg (Study 1) } & ITT population & 206 & 203 & 105 \\
\hline & Age, $[$ years $($ mean + SD)] & $22.4(4.62)$ & $22.7(4.85)$ & $22.5(4.24)$ \\
\hline & Gender ratio, male:female $(\%)$ & $44.7: 55.3$ & 41.9:58.1 & $50.5: 49.5$ \\
\hline & 11-point intensity [mean (SD)] & $6.6(1.14)$ & $6.5(1.07)$ & $6.6(1.17)$ \\
\hline & Categorical pain intensity (\%) & & & \\
\hline & Moderate & 80.6 & 80.3 & 79.0 \\
\hline & Severe & 19.4 & 19.7 & 21.0 \\
\hline & Number of molars removed $(\%)$ & & & \\
\hline & 1 & 17.0 & 21.2 & 17.1 \\
\hline & 2 & 82.0 & 78.3 & 79.0 \\
\hline & 3 & 1.0 & 0.5 & 3.8 \\
\hline & Tooth sites $(\%)^{\mathrm{a}}$ & & & \\
\hline & Left upper third molar & 35.9 & 32.5 & 35.2 \\
\hline & Left lower third molar & 43.7 & 38.9 & 41.0 \\
\hline & Right upper third molar & 46.6 & 48.8 & 50.5 \\
\hline & Right lower third molar & 57.8 & 59.1 & 60.0 \\
\hline & Impaction score $(\%)^{\mathrm{a}}$ & & & \\
\hline & Erupted in tissue & 23.3 & 26.6 & 24.8 \\
\hline & Broken soft tissue & 10.2 & 13.8 & 21.0 \\
\hline & Partial bony impaction & 38.3 & 32.5 & 29.5 \\
\hline & Full bony impaction & 85.9 & 86.7 & 85.7 \\
\hline \multirow[t]{22}{*}{325 mg (Study 2) } & ITT population & 200 & 200 & 100 \\
\hline & Age, years [mean (SD)] & $20.3(3.33)$ & $20.8(4.05)$ & $20.7(3.57)$ \\
\hline & Gender ratio, male:female $(\%)$ & $31.5: 68.5$ & $41.5: 58.5$ & $34.0: 66.0$ \\
\hline & 11-point intensity [mean (SD)] & $7.3(1.30)$ & $7.4(1.35)$ & $7.5(1.40)$ \\
\hline & Categorical pain intensity (\%) & & & \\
\hline & Moderate & 57.0 & 55.5 & 56.0 \\
\hline & Severe & 43.0 & 44.5 & 44.0 \\
\hline & Number of molars removed $(\%)$ & & & \\
\hline & 1 & 6.0 & 3.0 & 8.0 \\
\hline & 2 & 87.5 & 88.0 & 88.0 \\
\hline & 3 & 0 & 0 & 0 \\
\hline & 4 & 6.5 & 9.0 & 4.0 \\
\hline & Tooth sites $(\%)^{\mathrm{a}}$ & & & \\
\hline & Left upper third molar & 66.0 & 59.0 & 61.0 \\
\hline & Left lower third molar & 69.0 & 65.0 & 68.0 \\
\hline & Right upper third molar & 65.5 & 66.5 & 61.0 \\
\hline & Right lower third molar & 68.5 & 73.5 & 66.0 \\
\hline & Impaction score $(\%)^{\mathrm{a}}$ & & & \\
\hline & Erupted in tissue & 9.0 & 8.5 & 14.0 \\
\hline & Broken soft tissue & 5.5 & 8.5 & 8.0 \\
\hline & Partial bony impaction & 45.0 & 50.0 & 41.0 \\
\hline & Full bony impaction & 84.5 & 79.5 & 88.0 \\
\hline
\end{tabular}

${ }^{\text {a }}$ Patients may have had more than one affected tooth site or impaction score

The SPID and TOTPAR measurements showed the same consistent pattern as Study 1 for the comparisons between FR-aspirin, R-aspirin and placebo. At $2 \mathrm{~h}$, differences between FR-aspirin and R-aspirin were significant $(p<0.001$ SPID and TOTPAR) and both actives were statistically superior compared with placebo $(p<0.001)$. 


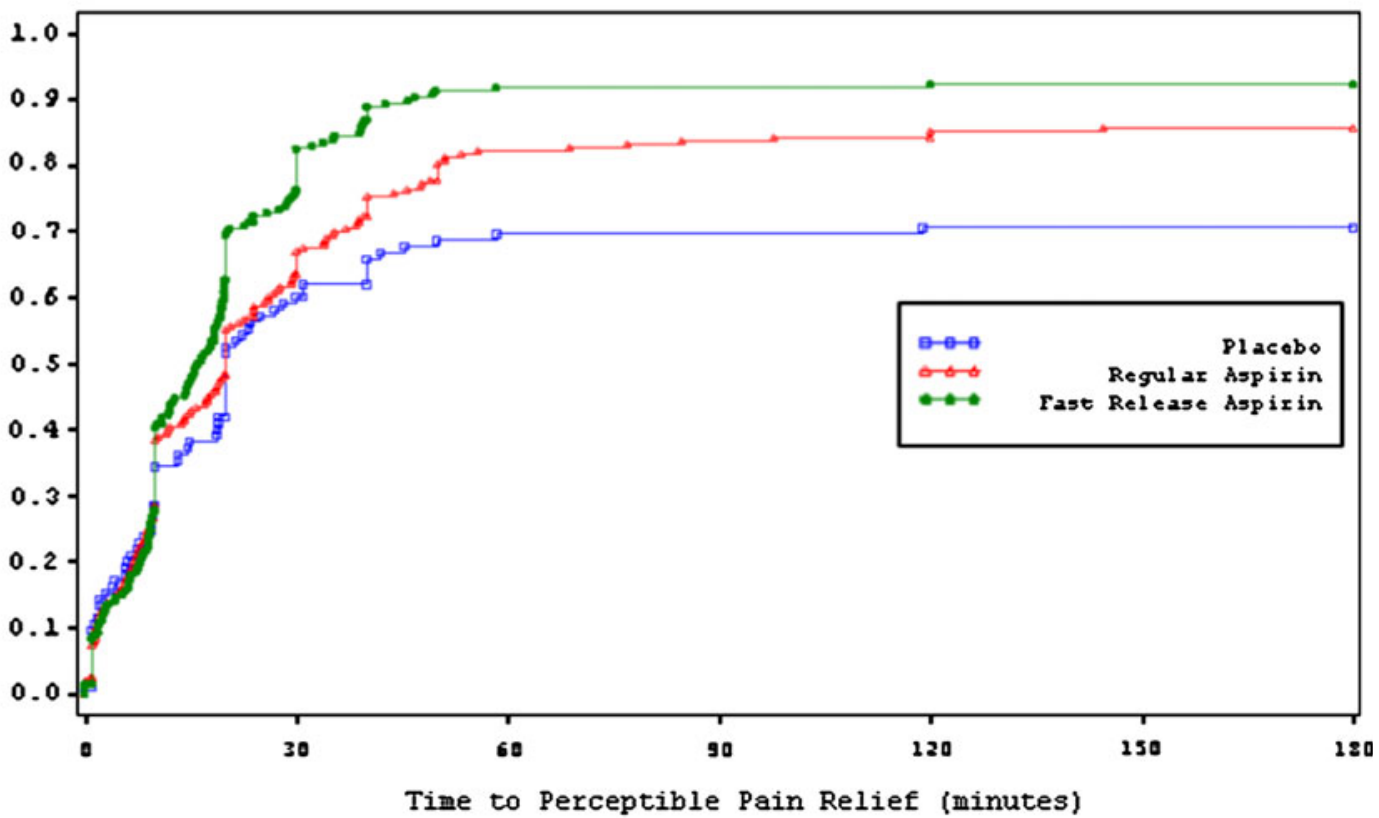



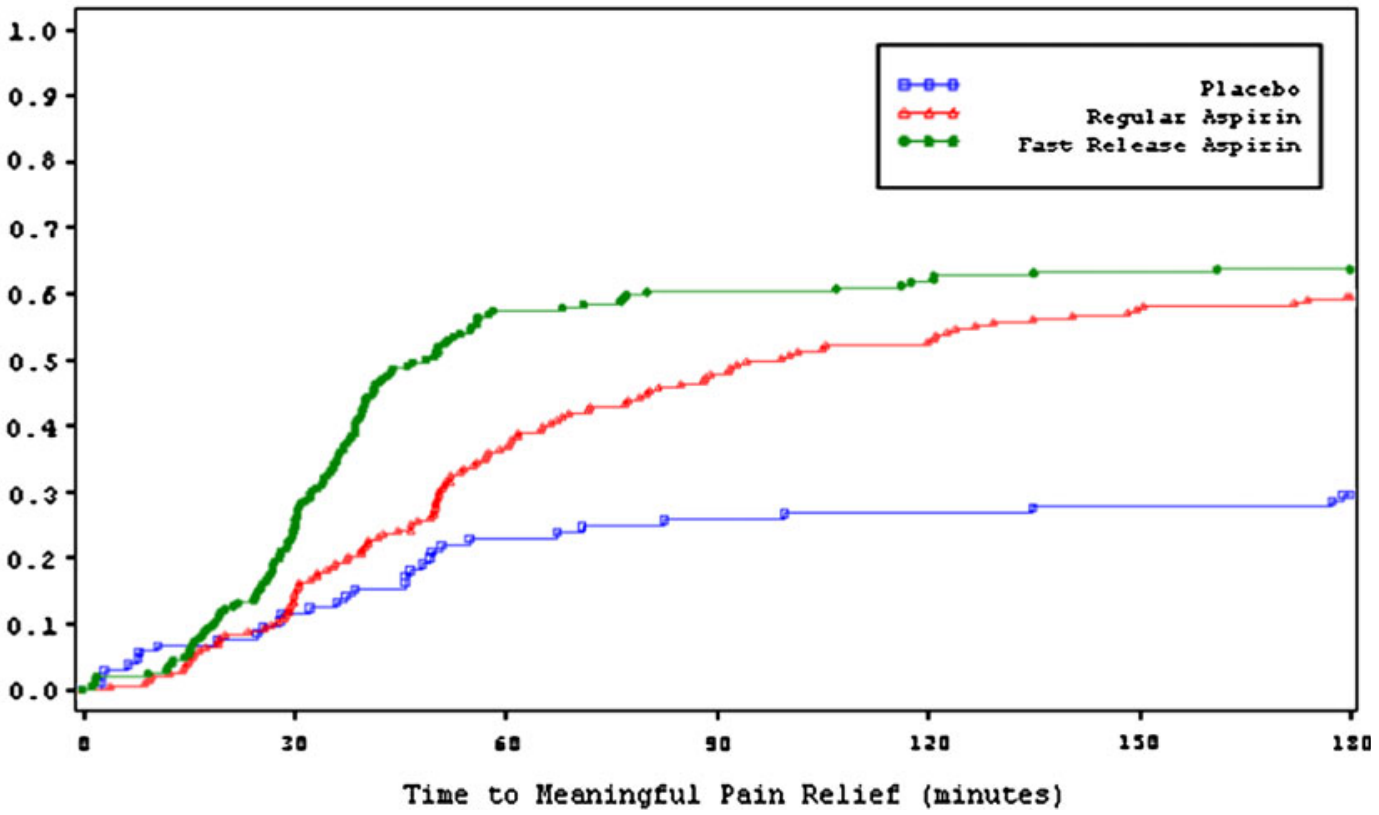

Fig. 1 Kaplan-Meier plot of time to first perceptible and meaningful pain relief from aspirin $500 \mathrm{mg}$

Similar to Study 1, for the 4- and 6-h SPID and TOTPAR measurements, the aspirin groups were not different; whereas both were statistically significantly greater than placebo (Table 2).

With respect to global evaluation, the majority of subjects treated with FR-aspirin and R-aspirin assessed as "fair" or better; while the majority of subjects treated with placebo assessed as "poor". More subjects treated with FR-aspirin assessed as very good or excellent (22.0 and
$12.5 \%)$ compared with R-aspirin $[19.5$ and $8.9 \%$ (Table 3)].

Both active treatments were well tolerated. In this study, there was one aspirin $325 \mathrm{mg}$ subject in the R-aspirin group, who experienced a serious adverse event of gastritis that was considered not related to the study drug, and two subjects ( 1 in the R-aspirin group and 1 in the placebo group) who discontinued due to non-serious adverse events. 


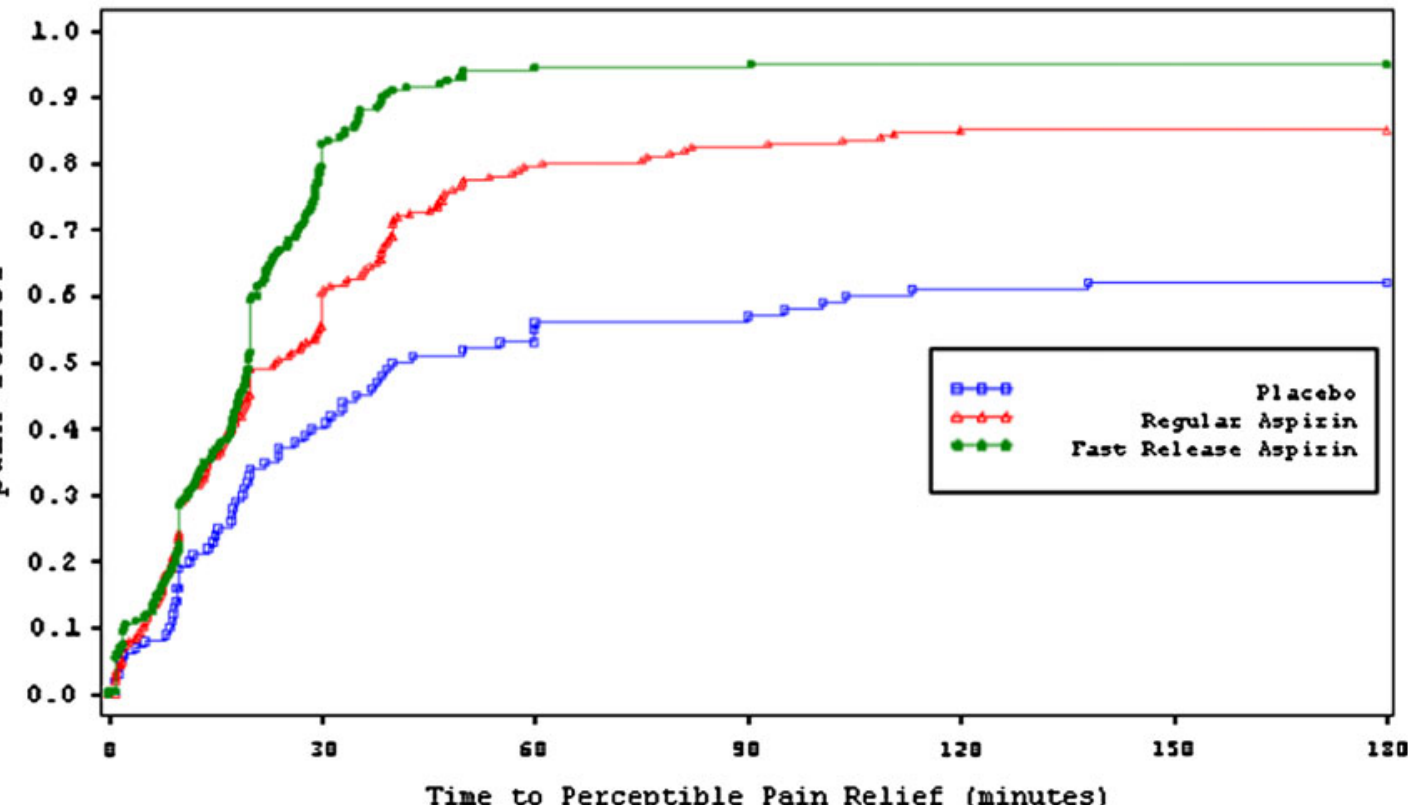



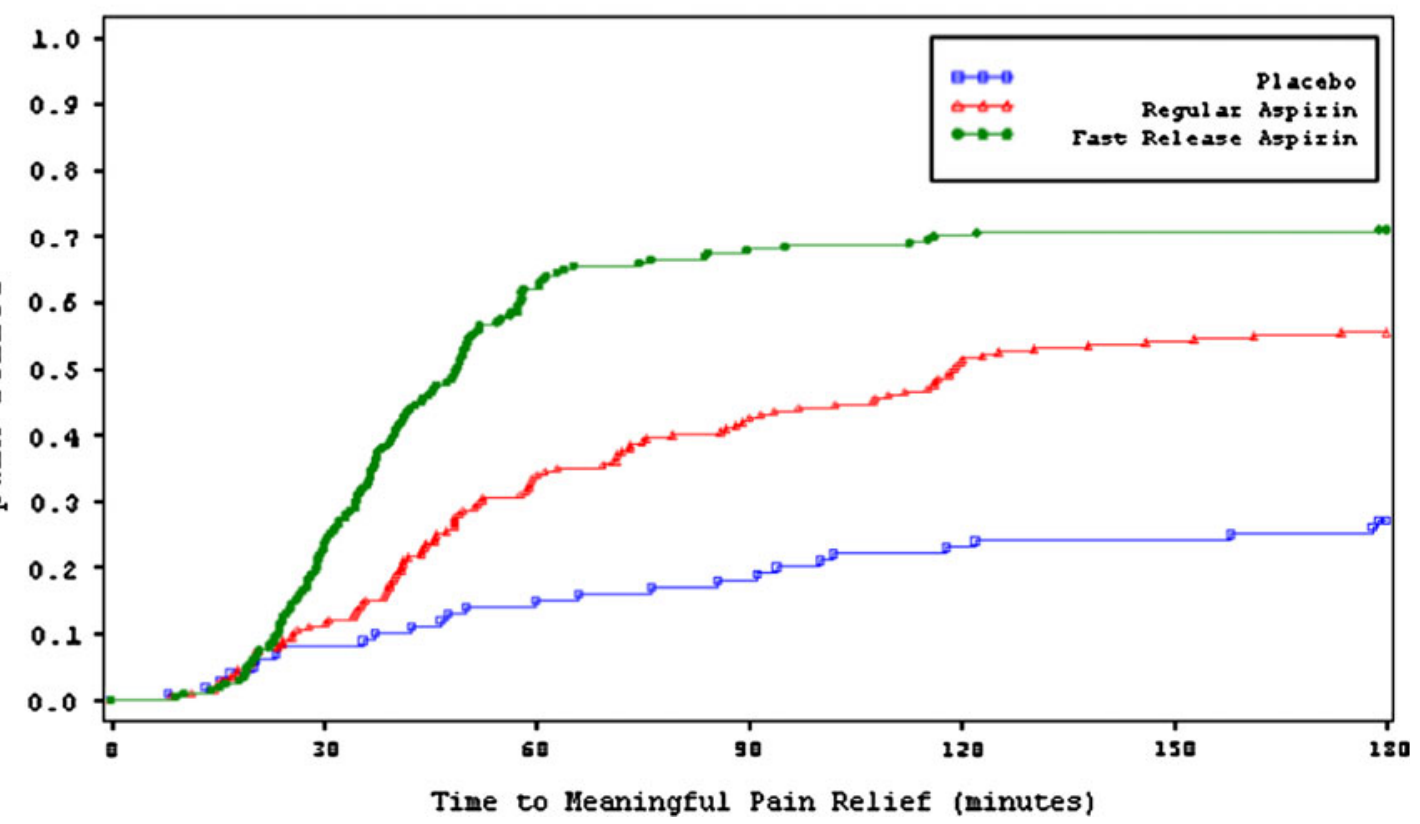

Fig. 2 Kaplan-Meier plot of time to first perceptible and meaningful pain relief from aspirin $325 \mathrm{mg}$

In both studies, the percentages of patients taking rescue medication $(1,000 \mathrm{mg}$ study: $\mathrm{FR}$-aspirin $=57.8 \%$, R-aspirin $=49.8 \%$, placebo $=68.6 \%$ and $650 \mathrm{mg}$ study: FR-aspirin $=59.0 \%$, R-aspirin $=51.0 \%$, placebo $=72.0 \%$ ) and the median times to rescue medication $(1,000 \mathrm{mg}$ study: FR-aspirin $=252 \mathrm{~min}, \quad \mathrm{R}$-aspirin $>360 \mathrm{~min}, \quad$ placebo $=$ $124 \mathrm{~min}$ and $650 \mathrm{mg}$ study: FR-aspirin $=268 \mathrm{~min}$, $\mathrm{R}$-aspirin $=322 \mathrm{~min}$, placebo $=105 \mathrm{~min}$ ) were not statistically significantly different between active treatments, but both actives were significantly better than placebo $(p<0.001)$.

\section{Safety results}

Adverse events of the individual studies are shown in Table 4. In Study 1, between 15 and $22 \%$ of subjects experienced at least one adverse event; in Study 2, 
Table 2 Time to relief and efficacy results

\begin{tabular}{|c|c|c|c|c|}
\hline Study & Variable & Aspirin fast-release tablet & Aspirin regular tablet & Placebo \\
\hline \multirow[t]{28}{*}{500 mg (Study 1) } & Median time to FPR, $\min (95 \% \mathrm{CI})$ & $16.3(12.2,19.2)$ & $20.0(15.7,23.4)$ & $20.0(18.9 .30 .0)$ \\
\hline & $p$ value versus fast-release aspirin & - & 0.004 & $<0.001$ \\
\hline & $p$ value versus regular aspirin & - & - & 0.014 \\
\hline & $\%$ of subjects achieved PR & 92.2 & 85.7 & 70.5 \\
\hline & $\%$ of subjects censored & 7.8 & 14.3 & 29.5 \\
\hline & Median time to $\mathrm{MR}, \min (95 \% \mathrm{CI})$ & $49.4(40.2,57.7)$ & $99.2(77.0,148.3)$ & NA (NA, NA) \\
\hline & $p$ value versus fast-release aspirin & - & 0.038 & $<0.001$ \\
\hline & $p$ value versus regular aspirin & - & - & $<0.001$ \\
\hline & $\%$ of subjects achieved PR & 65.0 & 62.1 & 37.1 \\
\hline & $\%$ of subjects censored & 35.0 & 37.9 & 62.9 \\
\hline & SPID 0-2 h, mean (SD) & $1.3(1.5)$ & $1.0(1.5)$ & $0.2(1.3)$ \\
\hline & $p$ value versus fast-release aspirin & - & 0.026 & $<0.001$ \\
\hline & $p$ value versus regular aspirin & - & - & $<0.001$ \\
\hline & SPID 0-4 h, mean (SD) & $1.9(3.2)$ & $2.0(3.4)$ & $0.3(3.2)$ \\
\hline & $p$ value versus fast-release aspirin & - & 0.922 & $<0.001$ \\
\hline & $p$ value versus regular aspirin & - & - & $<0.001$ \\
\hline & SPID 0-6 h, mean (SD) & $2.3(4.7)$ & $2.8(5.3)$ & $0.5(5.2)$ \\
\hline & $p$ value versus fast-release aspirin & - & 0.403 & 0.003 \\
\hline & $p$ value versus regular aspirin & - & - & $<0.001$ \\
\hline & TOTPAR 0-2 h, mean (SD) & $3.3(2.2)$ & $2.8(2.2)$ & $1.7(2.0)$ \\
\hline & $p$ value versus fast-release aspirin & - & 0.018 & $<0.001$ \\
\hline & $p$ value versus regular aspirin & - & - & $<0.001$ \\
\hline & TOTPAR 0-4 h, mean (SD) & $5.7(4.5)$ & $5.6(4.8)$ & $3.5(4.6)$ \\
\hline & $p$ value versus fast-release aspirin & - & 0.882 & $<0.001$ \\
\hline & $p$ value versus regular aspirin & - & - & $<0.001$ \\
\hline & TOTPAR 0-6 h, mean (SD) & $7.6(6.6)$ & $8.0(7.5)$ & $5.5(7.6)$ \\
\hline & $p$ value versus fast-release aspirin & - & 0.463 & 0.013 \\
\hline & $p$ value versus regular aspirin & - & - & 0.002 \\
\hline \multirow[t]{20}{*}{325 mg (Study 2) } & Median Time to FPR, $\min (95 \% \mathrm{CI})$ & $19.8(18.2,20.0)$ & $23.7(19.2,30.0)$ & $41.4(30.7$ 103.9) \\
\hline & $p$ value versus fast-release aspirin & - & $<0.001$ & $<0.001$ \\
\hline & $p$ value versus regular aspirin & - & - & $<0.001$ \\
\hline & $\%$ of subjects achieved PR & 95.0 & 85.0 & 62.0 \\
\hline & $\%$ of subjects censored & 5.0 & 15.0 & 38.0 \\
\hline & Median time to $\mathrm{MR}, \min (95 \% \mathrm{CI})$ & $48.9(41.8,54.5)$ & $119.2(93.6,192.3)$ & NA (NA, NA) \\
\hline & $p$ value versus fast-release aspirin & - & $<0.001$ & $<0.001$ \\
\hline & $p$ value versus regular aspirin & - & - & $<0.001$ \\
\hline & $\%$ of subjects achieved PR & 72.5 & 59.0 & 30.0 \\
\hline & $\%$ of subjects censored & 27.5 & 41.0 & 70.0 \\
\hline & SPID 0-2 h, mean (SD) & $1.7(1.6)$ & $1.2(1.5)$ & $0.1(1.2)$ \\
\hline & $p$ value versus fast-release aspirin & - & $<0.001$ & $<0.001$ \\
\hline & $p$ value versus regular aspirin & - & - & $<0.001$ \\
\hline & SPID 0-4 h, mean (SD) & $2.8(3.5)$ & $2.7(3.4)$ & $0.3(2.7)$ \\
\hline & $p$ value versus fast-release aspirin & - & 0.668 & $<0.001$ \\
\hline & $p$ value versus regular aspirin & - & - & $<0.001$ \\
\hline & SPID 0-6 h, mean (SD) & $3.5(5.4)$ & $3.8(5.3)$ & $0.6(4.5)$ \\
\hline & $p$ value versus fast-release aspirin & - & 0.631 & $<0.001$ \\
\hline & $p$ value versus regular aspirin & - & - & $<0.001$ \\
\hline & TOTPAR 0-2 h, mean (SD) & $3.6(2.1)$ & $2.7(2.1)$ & $1.1(1.4)$ \\
\hline
\end{tabular}


Table 2 continued

\begin{tabular}{|c|c|c|c|c|}
\hline Study & Variable & Aspirin fast-release tablet & Aspirin regular tablet & Placebo \\
\hline & $p$ value versus fast-release aspirin & - & $<0.001$ & $<0.001$ \\
\hline & $p$ value versus regular aspirin & - & - & $<0.001$ \\
\hline & TOTPAR 0-4 h, mean (SD) & $6.3(4.8)$ & $6.0(4.8)$ & $2.3(3.4)$ \\
\hline & $p$ value versus fast-release aspirin & - & 0.437 & $<0.001$ \\
\hline & $p$ value versus regular aspirin & - & - & $<0.001$ \\
\hline & TOTPAR 0-6 h, mean (SD) & $8.5(7.4)$ & $8.6(7.4)$ & $3.7(5.7)$ \\
\hline & $p$ value versus fast-release aspirin & - & 0.875 & $<0.001$ \\
\hline & $p$ value versus regular aspirin & - & - & $<0.001$ \\
\hline
\end{tabular}

FPR first perceptible pain relief, MR meaningful relief, $C I$ confidence interval, SPID summed pain intensity differences, TOTPAR total pain relief. $N A$ not available

Table 3 Global assessment of treatments

\begin{tabular}{lllll}
\hline Study & Variable & $\begin{array}{l}\text { Aspirin } \\
\text { fast-release } \\
\text { tablet }(\%)\end{array}$ & $\begin{array}{l}\text { Aspirin } \\
\text { regular } \\
\text { tablet }(\%)\end{array}$ & $\begin{array}{l}\text { Placebo } \\
(\%)\end{array}$ \\
\hline $500 \mathrm{mg}$ (Study 1) & Poor & 25.7 & 31.5 & 58.1 \\
& Fair & 26.2 & 20.7 & 13.3 \\
& Good & 22.3 & 28.1 & 19.0 \\
& Very good & 18.0 & 13.8 & 5.7 \\
& Excellent & 6.3 & 5.4 & 2.9 \\
$325 \mathrm{mg}$ (Study 2) & Poor & 19.5 & 29.0 & 60.0 \\
& Fair & 16.5 & 18.5 & 17.0 \\
& Good & 29.0 & 24.0 & 16.0 \\
& Very good & 22.0 & 19.5 & 5.0 \\
& Excellent & 12.5 & 8.0 & 0.0 \\
\hline
\end{tabular}

between 14 and 18\%. Gastrointestinal adverse events appeared between 4 and $8 \%$ in Study 1 and between 5 and $8 \%$ in Study 2. The most common GI adverse event was nausea.

\section{Discussion}

If an analgesic works fast, the consumers get the relief they seek and then there is less likelihood of taking additional medication that can result in unwanted side effects. In the recent past, several OTC analgesics were introduced as softgel or liquigel formulations with the putative advantage of a faster onset of action (Doyle et al. 2002). Interestingly, to our knowledge, none of these analgesics has ever directly compared the new formulation to the original formulation in a double-blinded efficacy study. These drugs rely on dissolution and pharmacokinetic data to justify their putative onset advantage; but this is not necessarily directly correlated into a clinical advantage. In the two studies presented, the efficacy data clearly demonstrate that the new formulation of aspirin has a faster onset of action at both the $650 \mathrm{mg}$ and $1,000 \mathrm{mg}$ doses. For the aspirin $650 \mathrm{mg}$ dose, the median time to meaningful relief was $70.3 \mathrm{~min}$ faster than regular aspirin, and for the $1,000 \mathrm{mg}$ aspirin dose, the median time to meaningful relief was $49.8 \mathrm{~min}$ faster than regular aspirin. From a clinical standpoint, this is a very relevant advantage and was accomplished without the addition of any active adjuvant such as caffeine. This advanced aspirin formulation was accomplished by incorporating an effervescent component (sodium carbonate) and micronized active ingredient. Unlike a softgel or liquigel formulation, this aspirin formulation retains the advantage of still being a tablet.

Furthermore, the overall efficacy of the FR-aspirin tablet was sustained as shown by the non-significant differences between FR-aspirin and R-aspirin for the SPID- and TOTPAR measurements and the use of rescue medication over the 6-h observation period.

The dental impaction pain model was chosen for these studies because of its proven validity, reliability and sensitivity. The results of these two studies are consistent with previous dental studies and there was a strong correlation between the improved pharmacokinetics of the new aspirin formulation and clinical efficacy.

It can be postulated that the minor outcome differences between the two studies can be explained by the expected variability between the two different study sites. Furthermore, distribution of baseline pain intensity was different in the two studies. However, the results of the two studies were remarkably consistent and supportive of the faster onset for the FR-aspirin formulations. 
Table 4 Treatment emergent adverse events of individual studies with aspirin frequencies $>1 \%$ [number (percentages)]

\begin{tabular}{|c|c|c|c|c|c|c|}
\hline \multirow{2}{*}{$\begin{array}{l}\text { Study } \\
\text { Variable }\end{array}$} & \multicolumn{3}{|c|}{ Study 1 aspirin $1,000 \mathrm{mg}$} & \multicolumn{3}{|c|}{ Study 2 aspirin $650 \mathrm{mg}$} \\
\hline & $\begin{array}{l}\text { Aspirin fast-release } \\
\text { tablet }\end{array}$ & $\begin{array}{l}\text { Aspirin regular } \\
\text { tablet }\end{array}$ & Placebo & $\begin{array}{l}\text { Aspirin fast-release } \\
\text { tablet }\end{array}$ & $\begin{array}{l}\text { Aspirin regular } \\
\text { tablet }\end{array}$ & Placebo \\
\hline Total number of patients treated & 206 & 203 & 105 & 200 & 200 & 100 \\
\hline Total number of adverse events & 50 & 36 & 36 & 41 & 39 & 23 \\
\hline $\begin{array}{l}\text { Number of subjects with at } \\
\text { least one adverse event }\end{array}$ & $38(18.4 \%)$ & $31(15.3 \%)$ & $23(21.9 \%)$ & $29(14.5 \%)$ & $30(15.0 \%)$ & $18(18.0 \%)$ \\
\hline Gastrointestinal disorders & $10(4.9 \%)$ & $8(3.9 \%)$ & $8(7.6 \%)$ & $13(6.5 \%)$ & $10(5.0 \%)$ & $8(8.0 \%)$ \\
\hline Nausea & $8(3.9 \%)$ & $6(3.0 \%)$ & $5(4.8 \%)$ & $9(4.5 \%)$ & $5(2.5 \%)$ & $6(6.0 \%)$ \\
\hline Vomiting & $5(2.4 \%)$ & $1(0.5 \%)$ & $3(2.9 \%)$ & $3(1.5 \%)$ & $2(1.0 \%)$ & $1(1.0 \%)$ \\
\hline Nervous system disorders & $12(5.8 \%)$ & $16(7.9 \%)$ & $13(12.4 \%)$ & $5(2.5 \%)$ & $11(5.5 \%)$ & $5(5.0 \%)$ \\
\hline Dizziness & $4(1.9 \%)$ & $2(1.0 \%)$ & $2(1.9 \%)$ & $4(2.0 \%)$ & $3(1.5 \%)$ & $3(3.0 \%)$ \\
\hline Headache & $8(3.9 \%)$ & $14(6.9 \%)$ & $9(8.6 \%)$ & $1(0.5 \%)$ & $8(4.0 \%)$ & $1(1.0 \%)$ \\
\hline Infections and infestations & $13(6.3 \%)$ & $9(4.4 \%)$ & $5(4.8 \%)$ & $9(4.5 \%)$ & $8(4.0 \%)$ & $3(3.0 \%)$ \\
\hline Alveolar osteitis & $12(5.8 \%)$ & $9(4.4 \%)$ & $5(4.8 \%)$ & $6(3.0 \%)$ & $6(3.0 \%)$ & $3(3.0 \%)$ \\
\hline
\end{tabular}

\section{Conclusions}

The two efficacy studies described in this paper clearly demonstrate that the onset of analgesic efficacy is improved by adding an effervescent component (sodium carbonate) and micronized active ingredient to the aspirin formulation. The enhanced onset did not adversely impact either the peak effect or duration of effect compared to regular aspirin. In addition, the side effect data from these single dose studies did not indicate any change in the side effect profile. The initial findings of significantly improved dissolution and pharmacokinetic profiles for this new rapidly acting aspirin formulation were confirmed in these two well-controlled efficacy studies.

Acknowledgments The investigators William L. Buchanan, MD, DDS, PPD Development, Austin, TX, USA and Lynn R. Webster, MD, Lifetreee Clinical Research, Salt Lake City, UT, USA participated in conducting the study with fast-release aspirin500 mg (Study 1). The investigators Patrick R. Brain, DDS, Jean Brown Research, Salt Lake City, UT, USA and Stephen E. Daniels, DO, Premier Research Group, Austin, TX, USA participated in conducting the study with fast-release aspirin $325 \mathrm{mg}$ (Study 2). The two studies were funded by Bayer Consumer Care, Morristown, NJ, USA.

Open Access This article is distributed under the terms of the Creative Commons Attribution License which permits any use, distribution, and reproduction in any medium, provided the original author(s) and the source are credited.

\section{References}

Bachert C, Chuchalin AG, Eisebitt R et al (2005) Aspirin compared with acetaminophen in the treatment of fever and other symptoms of upper respiratory tract infection in adults: a multicenter, randomized, double-blind, double-dummy, placebo- controlled, parallel-group, single-dose, 6-hour dose-ranging study. Clin Therapeutics 27:993-1003

Cooper SA (1981a) Comparative analgesic efficacies of aspirin and acetaminophen. Arch Intern Med 141:282-285

Cooper SA (1981b) Oral analgesics used to treat dental pain. Clin Prevent Dent 3:28-32

Cooper SA (1983) Models for clinical assessment of oral analgesics. Am J Med 75:24-29

Cooper SA, Desjardins PJ (2010) The Value of the dental impaction pain model In: Szallasi A (ed) Drug Development Analgesia, Methods in Molecular Biology Series, The Humana Press

Desjardins PJ, Black P, Papageorge M et al (2002) Ibuprofen arginate provides effective relief from postoperative dental pain with more rapid onset of action than ibuprofen. Europ J Clin Pharmacol 58:387-394

Diener HC, Eikerman A, Gessner U et al (2004a) Efficacy of $1,000 \mathrm{mg}$ effervescent acetylsalicylic acid and sumatriptan in treating associated migraine symptoms. Eur Neurol 52:50-56

Diener HC, Bussone G, de Liano H et al (2004b) Placebo-controlled comparison of effervescent acetylsalicylic acid, sumatriptan and ibuprofen in the treatment of migraine attacks. Cephalalgia 24:947-954

Diener HC, Lampl C, Reimnitz P, Voelker M (2006) Aspirin in the treatment of acute migraine attacks. Expert Rev Neurotherapeutics 6:563-573

Doyle G, Jayawardena S, Ashraf E, Cooper SA (2002) Efficacy and tolerability of nonprescription ibuprofen versus celecoxib for dental pain. J Clin Pharmacol 42:912-919

Eccles R, Loose I, Jawad M, Nyman L (2003) Effects of acetylsalicylic acid on sore throat pain and other pain symptoms associated with acute upper respiratory tract infection. Pain Medicine 4:118-124

European Medicine Agency. Committee for proprietary medicinal products. Note for guidance on clinical investigations of medicinal products for treatment of nociceptive pain. London, 21 November 2002 CPMP/EWP/612/00

Food and drug administration (1977) Establishment of a monograph for OTC internal analgesic, antipyretic, and antirheumatic products 42(131):35345-621 (Docket No. 77 N-0094)

Forbes JA, Edquist IA, Smith FG et al (1991) Evaluation of bromfenac, aspirin, and ibuprofen in postoperative oral surgery pain. Pharmacotherapy 11:64-70 
Forbes JA, Beaver WT, Jones KF et al (1992) Analgesic efficacy of bromfenac, ibuprofen, and aspirin in postoperative oral surgery pain. Clin Pharmacol Ther 51:343-352

Lampl C, Voelker M, Diener HC (2007) Efficacy and safety of $1,000 \mathrm{mg}$ effervescent aspirin: individual patient data metaanalysis of three trials in migraine headache and migraine accompanying symptoms. J Neurol 254:705-712

Lange R, Schwarz JA, Hohn M (2000) Acetylsalicylic acid effervescent $1,000 \mathrm{mg}\left(\right.$ Aspirin $\left.^{\circledR}\right)$ in acute migraine attacks; a multicentre, randomized, double-blind, single-dose, placebocontrolled parallel group study. Cephalalgia 20:663-667

Lipton RB, Goldstein J, Baggish JS et al (2005) Aspirin is efficacious for the treatment of acute migraine. Headache 45:283-292

MacEachern L, Garreffa S, Plaza D, Koslo R (2002) Aspirin is efficacious for treatment of severe pain associated with tension headache. J Pain 2:40

MacGregor AE, Dowson A, Davies PTG (2002) Mouth-dispersible aspirin in the treatment of migraine: a placebo-controlled study. Headache 42:249-255
Martinez-Martin P, Raffaelli E Jr, Titus F (2001) Efficacy and safety of metamizol versus acetylsalicylic acid in patients with moderate episodic tension-type headache: a randomized, double-blind, placebo- and active-controlled, multicentre study. Cephalalgia 21:604-610

Steiner TJ, Lange R, Voelker M (2003) Aspirin in episodic tensiontype headache: placebo-controlled dose-ranging comparison with paracetamol. Cephalalgia 23:59-66

Voelker M, Hammer M (2011) Dissolution and pharmacokinetics of a novel micronized aspirin formulation. Inflammopharmacol. doi: 10.1007/s10787-011-0099-z

Zhang WY, Li Wan Po A (1998) Efficacy of minor analgesics in primary dysmenorrhoea: a systematic review. $\mathrm{Br} \mathrm{J}$ Obstet Gynaecol 105:780-789 